\title{
The Public Health and Economic Benefits of Taxing Sugar-Sweetened Beverages
}

\author{
Kelly D. Brownell, Ph.D., Thomas Farley, M.D., M.P.H., Walter C. Willett, M.D., Dr.P.H., \\ Barry M. Popkin, Ph.D., Frank J. Chaloupka, Ph.D., Joseph W. Thompson, M.D., M.P.H., \\ and David S. Ludwig, M.D., Ph.D.
}

The consumption of sugar-sweetened beverages has been linked to risks for obesity, diabetes, and heart disease $\mathrm{e}^{1-3}$; therefore, a compelling case can be made for the need for reduced consumption of these beverages. Sugar-sweetened beverages are beverages that contain added, naturally derived caloric sweeteners such as sucrose (table sugar), high-fructose corn syrup, or fruit-juice concentrates, all of which have similar metabolic effects.

Taxation has been proposed as a means of reducing the intake of these beverages and thereby lowering health care costs, as well as a means of generating revenue that governments can use for health programs. ${ }^{4-7}$ Currently, 33 states have sales taxes on soft drinks (mean tax rate, 5.2\%), but the taxes are too small to affect consumption and the revenues are not earmarked for programs related to health. This article examines trends in the consumption of sugar-sweetened beverages, evidence linking these beverages to adverse health outcomes, and approaches to designing a tax system that could promote good nutrition and help the nation recover health care costs associated with the consumption of sugarsweetened beverages.

\section{CONSUMPTION TRENDS}

AND HEALTH OUTCOMES

In recent decades, intake of sugar-sweetened beverages has increased around the globe; for example, intake in Mexico doubled between 1999 and 2006 across all age groups. ${ }^{8}$ Between 1977 and 2002, the per capita intake of caloric beverages doubled in the United States across all age groups $^{9}$ (Fig. 1). The most recent data (2005-2006) show that children and adults in the United States consume about 172 and $175 \mathrm{kcal}$ daily, respectively, per capita from sugar-sweetened beverages.
The relationship between the consumption of sugar-sweetened beverages and body weight has been examined in many cross-sectional and longitudinal studies and has been summarized in systematic reviews. ${ }^{1,2}$ A meta-analysis showed positive associations between the intake of sugarsweetened beverages and body weight - associations that were stronger in longitudinal studies than in cross-sectional studies and in studies that were not funded by the beverage industry than in those that were. ${ }^{2}$ A meta-analysis of studies involving children ${ }^{10}$ - a meta-analysis that was supported by the beverage industry was interpreted as showing that there was no evidence of an association between consumption of sugar-sweetened beverages and body weight, but it erroneously gave large weight to several small negative studies; when a more realistic weighting was used, the meta-analysis summary supported a positive association. ${ }^{11} \mathrm{~A}$ prospective study involving middle-school students over the course of 2 academic years showed that the risk of becoming obese increased by $60 \%$ for every additional serving of sugar-sweetened beverages per day. ${ }^{12}$ In an 8-year prospective study involving women, those who increased their consumption of sugar-sweetened beverages at year 4 and maintained this increase gained $8 \mathrm{~kg}$, whereas those who decreased their intake of sugar-sweetened beverages at year 4 and maintained this decrease gained only $2.8 \mathrm{~kg} .{ }^{13}$

Short-term clinical trials provide an experimental basis for understanding the way in which sugar-sweetened beverages may affect adiposity. Tordoff and Alleva ${ }^{14}$ found that as compared with total energy intake and weight during a 3-week period in which no beverages were provided, total energy intake and body weight increased when subjects were given $530 \mathrm{kcal}$ of sugar-sweetened beverages per day for 3 weeks but decreased when 


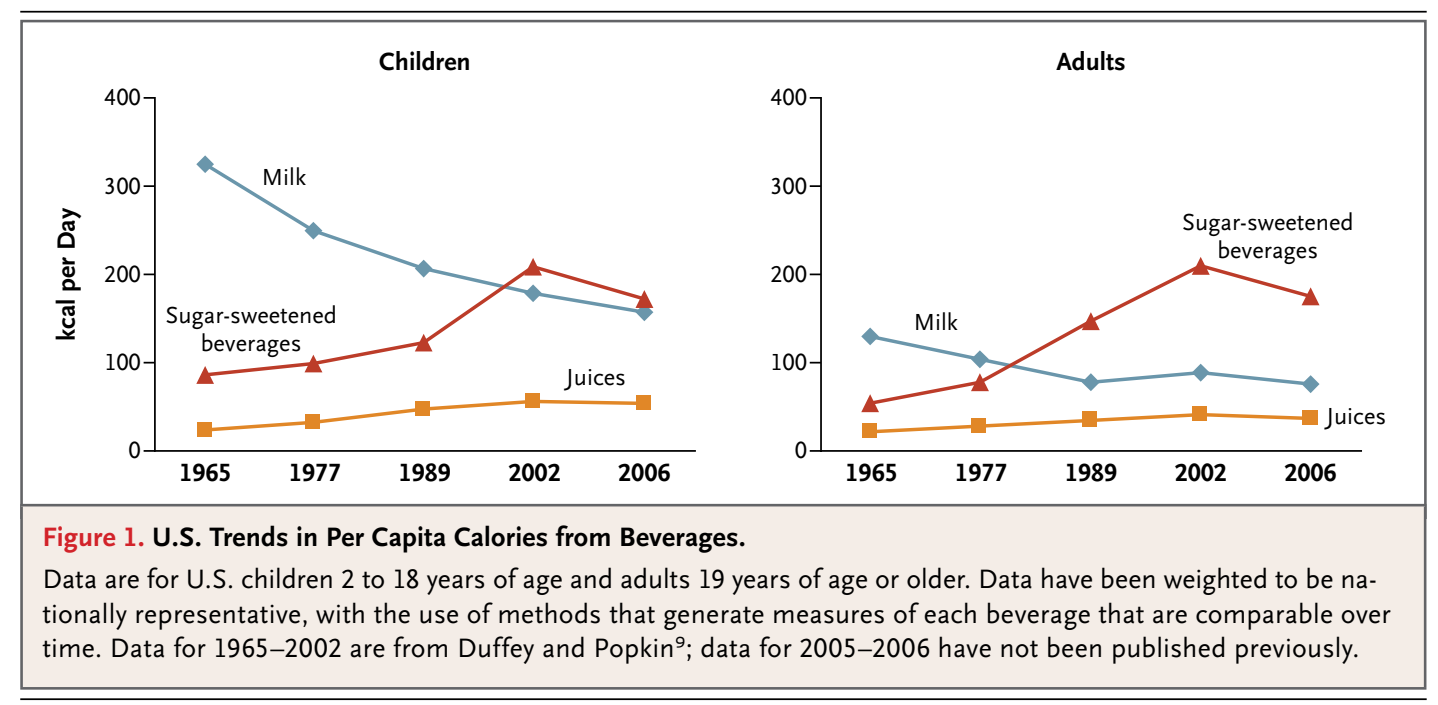

subjects were given noncaloric sweetened beverages for the same length of time. Raben et al. ${ }^{15}$ reported that obese subjects gained weight when they were given sucrose, primarily in the form of sugar-sweetened beverages, for 10 weeks, whereas they lost weight when they were given noncaloric sweeteners for the same length of time.

Four long-term, randomized, controlled trials examining the relationship between the consumption of sugar-sweetened beverages and body weight have been reported; the results showed the strongest effects among overweight persons. A school-based intervention to reduce the consumption of carbonated beverages was assessed among 644 students, 7 to 11 years of age, in the United Kingdom with the use of a cluster design. ${ }^{16}$ After 1 year, the intervention group, as compared with the control group, had a nonsignificantly lower mean body-mass index (the weight in kilograms divided by the square of the height in meters) and a significant $7.7 \%$ lower incidence of obesity. In a study involving 1140 Brazilian schoolchildren, 9 to 12 years of age, that was designed to discourage the consumption of sugarsweetened beverages, no overall effect on bodymass index was observed during the 9-month academic year. ${ }^{17}$ Among students who were overweight at baseline, the body-mass index was nonsignificantly decreased in the intervention group as compared with the control group; the difference was significant among overweight girls. In another clinical trial, 103 high-school students in Boston were assigned to a control group or to an intervention group that received home delivery of noncaloric beverages for 25 weeks. The body-mass index was nonsignificantly reduced in the overall intervention group, but among students in the upper third of body-mass index at baseline, there was a significant decrease in the body-mass index in the intervention group, as compared with the control group (a decrease of 0.63 vs. an increase of 0.12 ). ${ }^{18}$ The effects of replacing sugar-sweetened beverages with milk products were examined among 98 overweight Chilean children. ${ }^{19}$ After 16 weeks, there was a nonsignificantly lower increase in the percentage of body fat in the intervention group than in the control group $(0.36 \%$ and $0.78 \%$ increase, respectively), whereas there was a significantly greater increase in lean mass in the intervention group ( 0.92 vs. $0.62 \mathrm{~kg}$ ).

Three prospective, observational studies one involving nurses in the United States, one involving Finnish men and women, and one involving black women - each showed positive associations between the consumption of sugarsweetened beverages and the risk of type 2 diabetes. ${ }^{13,20,21}$ Among the 91,249 women in the Nurses' Health Study II who were followed for 8 years, the risk of diabetes among women who consumed one or more servings of sugar-sweetened beverages per day was nearly double the risk among women who consumed less than one serving of sugar-sweetened beverages per month ${ }^{13}$; about half the excess risk was accounted for by greater body weight. Among black women, excess weight accounted for most of the excess risk.

Among 88,520 women in the Nurses' Health 
Study, the risk of coronary heart disease among women who consumed one serving of sugarsweetened beverages per day, as compared with women who consumed less than one serving per month, was increased by $23 \%$, and among those who consumed two servings or more per day, the risk was increased by 35\%. ${ }^{3}$ Increased body weight explained some, but not all, of this association.

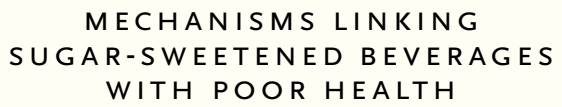

A variety of behavioral and biologic mechanisms may be responsible for the associations between the consumption of sugar-sweetened beverages and adverse health outcomes, with some links (e.g., the link between intake of sugar-sweetened beverages and weight gain) better established than others. The well-documented adverse physiological and metabolic consequences of a high intake of refined carbohydrates such as sugar include the elevation of triglyceride levels and of blood pressure and the lowering of high-density lipoprotein cholesterol levels, which would be expected to increase the risk of coronary heart disease. ${ }^{22}$ Because of the high glycemic load of sugar-sweetened beverages, consumption of these beverages would be expected to increase the risk of diabetes by causing insulin resistance and also through direct effects on pancreatic islet cells. ${ }^{23}$ Observational research has shown that consumption of sugar-sweetened beverages, but not of noncalorically sweetened beverages, is associated with markers of insulin resistance. ${ }^{24}$

Intake of sugar-sweetened beverages may cause excessive weight gain owing in part to the apparently poor satiating properties of sugar in liquid form. Indeed, adjustment of caloric intake at subsequent meals for energy that had been consumed as a beverage is less complete than adjustment of intake for energy that had been consumed as a solid food. ${ }^{25}$ For example, in a study involving 323 adults, in which 7-day food diaries were used, energy from beverages added to total energy intake instead of displacing other sources of calories. ${ }^{26}$ The results of a study of school-age children were consistent with the data from adults and showed that children who drank $9 \mathrm{oz}$ or more of sugar-sweetened beverages per day consumed nearly $200 \mathrm{kcal}$ per day more than those who did not drink sugar-sweetened beverages. ${ }^{27}$

Short-term studies of the effect of beverage consumption on energy intake support this mechanism. Among 33 adults who were given identical test lunches on six occasions but were given beverages of different types (sugar-sweetened cola, noncaloric cola, or water) and amounts $(12 \mathrm{oz}$ [355 ml] or $18 \mathrm{oz}[532 \mathrm{ml}]),{ }^{28}$ the intake of solid food did not differ across conditions; the result was that there was significantly greater total energy consumption when the sugarsweetened beverages were served.

Sugar-sweetened beverages may also affect body weight through other behavioral mechanisms. Whereas the intake of solid food is characteristically coupled to hunger, people may consume sugar-sweetened beverages in the absence of hunger, to satisfy thirst or for social reasons. Sugar-sweetened beverages may also have chronic adverse effects on taste preferences and food acceptance. Persons - especially children who habitually consume sugar-sweetened beverages rather than water may find more satiating but less sweet foods (e.g., vegetables, legumes, and fruits) unappealing or unpalatable, with the result that their diet may be of poor quality.

\section{ECONOMIC RATIONALE}

Economists agree that government intervention in a market is warranted when there are "market failures" that result in less-than-optimal production and consumption. ${ }^{29,30}$ Several market failures exist with respect to sugar-sweetened beverages. First, because many persons do not fully appreciate the links between consumption of these beverages and health consequences, they make consumption decisions with imperfect information. These decisions are likely to be further distorted by the extensive marketing campaigns that advertise the benefits of consumption. A second failure results from time-inconsistent preferences (i.e., decisions that provide short-term gratification but long-term harm). This problem is exacerbated in the case of children and adolescents, who place a higher value on present satisfaction while more heavily discounting future consequences. Finally, financial "externalities" exist in the market for sugar-sweetened beverages in that consumers do not bear the full costs of their consumption decisions. Because of the contribu- 
tion of the consumption of sugar-sweetened beverages to obesity, as well as the health consequences that are independent of weight, the consumption of sugar-sweetened beverages generates excess health care costs. Medical costs for overweight and obesity alone are estimated to be $\$ 147$ billion - or $9.1 \%$ of U.S. health care expenditures - with half these costs paid for publicly through the Medicare and Medicaid programs. ${ }^{31}$

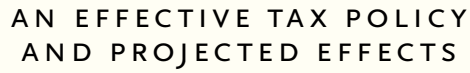

Key factors to consider in developing an effective policy include the definition of taxable beverages, the type of tax (sales tax or excise tax), and the tax rate. We propose an excise tax of 1 cent per ounce for beverages that have any added caloric sweetener. An alternative would be to tax beverages that exceed a threshold of grams of added caloric sweetener or of kilocalories per ounce. If this approach were used, we would recommend that the threshold be set at $1 \mathrm{~g}$ of sugar per ounce (30 ml) (32 kcal per 8 oz [237 ml]). Another option would be a tax assessed per gram of added sugar, but such an approach would be difficult to administer. The advantage of taxing beverages that have any added sugar is that this kind of tax is simpler to administer and it may promote the consumption of no-calorie beverages, most notably water; however, a threshold approach would also promote calorie reductions and would encourage manufacturers to reformulate products. A consumer who drinks a conventional soft drink (20 oz [591 ml]) every day and switches to a beverage below this threshold would consume approximately 174 fewer calories each day.

A specific excise tax (a tax levied on units such as volume or weight) per ounce or per gram of added sugar would be preferable to a sales tax or an ad valorem excise tax (a tax levied as a percentage of price) and would provide an incentive to reduce the amount of sugar per ounce of a sugar-sweetened beverage. Sales taxes added as a percentage of retail cost would have three disadvantages: they could simply encourage the purchase of lower-priced brands (thus resulting in no calorie reduction) or of large containers that cost less per ounce; consumers would become aware of the added tax only after making the decision to purchase the beverage; and the syrups that are used in fountain drinks, which are often served with multiple refills, would remain untaxed. A number of states currently exempt sugarsweetened beverages from sales taxes along with food, presumably because food is a necessity. This practice should be eliminated, whether or not an excise tax is enacted.

Excise taxes could be levied on producers and wholesalers, and the cost would almost certainly be passed along to retailers, who would then incorporate it into the retail price; thus, consumers would become aware of the cost at the point of making a purchase decision. Taxes levied on producers and wholesalers would be much easier to collect and enforce than taxes levied on retailers because of the smaller number of businesses that would have to comply with the tax; in addition, the sugar used in syrups could be taxed - a major advantage because of the heavy sales of fountain drinks. Experience with tobacco and alcohol taxes suggests that specific excise taxes have a greater effect on consumption than do ad valorem excise taxes and can also generate more stable revenues because they are less dependent on industry pricing strategies. ${ }^{32}$ In addition, tax laws should be written with provisions for the regular adjustment of specific excise taxes to keep pace with inflation, in order to prevent the effect of the taxes on both prices and revenues from eroding over time.

A tax of 1 cent per ounce of beverage would increase the cost of a $20-\mathrm{oz}$ soft drink by 15 to $20 \%$. The effect on consumption can be estimated through research on price elasticity (i.e., consumption shifts produced by price). The price elasticity for all soft drinks is in the range of -0.8 to $-1.0 .^{33}$ (Elasticity of -0.8 suggests that for every $10 \%$ increase in price, there would be a decrease in consumption of $8 \%$, whereas elasticity of -1.0 suggests that for every $10 \%$ increase in price, there would be a decrease in consumption of $10 \%$.) Even greater price effects are expected from taxing only sugar-sweetened beverages, since some consumers will switch to diet beverages. With the use of a conservative estimate that consumers would substitute calories in other forms for $25 \%$ of the reduced calorie consumption, an excise tax of 1 cent per ounce would lead to a minimum reduction of $10 \%$ in calorie consumption from sweetened beverages, or $20 \mathrm{kcal}$ per person per day, a reduction that is sufficient for weight loss and reduction in risk (unpublished 
data). The benefit would be larger among consumers who consume higher volumes, since these consumers are more likely to be overweight and appear to be more responsive to prices. ${ }^{7}$ Higher taxes would have greater benefits.

A controversial issue is whether to tax beverages that are sweetened with noncaloric sweeteners. No adverse health effects of noncaloric sweeteners have been consistently demonstrated, but there are concerns that diet beverages may increase calorie consumption by justifying consumption of other caloric foods or by promoting a preference for sweet tastes. ${ }^{34}$ At present, we do not propose taxing beverages with noncaloric sweeteners, but we recommend close tracking of studies to determine whether taxing might be justified in the future.

REVENUE-GENERATING POTENTIAL

The revenue generated from a tax on sugarsweetened beverages would be considerable and could be used to help support childhood nutrition programs, obesity-prevention programs, or health care for the uninsured or to help meet general revenue needs. A national tax of 1 cent per ounce on sugar-sweetened beverages would raise $\$ 14.9$ billion in the first year alone. Taxes at the state level would also generate considerable revenue - for example, \$139 million in Arkansas, \$183 million in Oregon, \$221 million in Alabama, \$928 million in Florida, \$937 million in New York, $\$ 1.2$ billion in Texas, and $\$ 1.8$ billion in California. A tax calculator that is available online can generate revenue numbers for states and 25 major cities. ${ }^{35}$

OBJECTIONS, INDUSTRY REACTION, PUBLIC SUPPORT, AND FRAMING

One objection to a tax on sugar-sweetened beverages is that it would be regressive. This argument arose with respect to tobacco taxes but was challenged successfully by proponents of the taxes, who pointed out that the poor face a disproportionate burden of smoking-related illnesses, that nearly all smokers begin to smoke when they are teenagers, and that both groups are sensitive to price changes. ${ }^{7}$ In addition, some of the tobacco revenue has been used for programs developed specifically for the poor and for youth. The poor are most affected by illnesses that are related to unhealthful diets, and brand loyalties for beverages tend to be set by the teenage years. In addition, sugar-sweetened beverages are not necessary for survival, and an alternative (i.e., water) is available at little or no cost; hence, a tax that shifted intake from sugar-sweetened beverages to water would benefit the poor both by improving health and by lowering expenditures on beverages. Designating revenues for programs promoting childhood nutrition, obesity prevention, or health care for the uninsured would preferentially help those most in need.

A second objection is that taxing sugarsweetened beverages will not solve the obesity crisis and is a blunt instrument that affects even those who consume small amounts of such beverages. Seat-belt legislation and tobacco taxation do not eliminate traffic accidents and heart disease but are nevertheless sound policies. Similarly, obesity is unlikely to yield to any single policy intervention, so it is important to pursue multiple opportunities to obtain incremental gains. Reducing caloric intake by 1 to $2 \%$ per year would have a marked impact on health in all age groups, and the financial burden on those who consumed small amounts of sugar-sweetened beverages would be minimal.

Opposition to a tax by the beverage industry is to be expected, given the possible effect on sales; opposition has been seen in jurisdictions that have considered such taxes and can be predicted from the behavior of the tobacco industry under similar circumstances. ${ }^{36}$ PepsiCo threatened to move its corporate headquarters out of New York when the state considered implementing an $18 \%$ sales tax on sugar-sweetened beverages. ${ }^{37}$ The tobacco industry fought policy changes by creating front groups with names that suggested community involvement. The beverage industry has created Americans Against Food Taxes. ${ }^{38}$ These reactions suggest that the beverage industry believes that a tax would have a substantial impact on consumption.

Public support for food and beverage taxes to address obesity has increased steadily. Questions about taxes in polls have been asked in various ways, and the results are therefore not directly comparable from year to year, but overall trends are clear. Support for food taxes rose from 33\% in 2001 to $41 \%$ in 2003 and then to $54 \%$ in 2004. ${ }^{39}$ A 2008 poll of New York State residents showed that $52 \%$ of respondents support a soda 
tax; $72 \%$ support such a tax if the revenue is used to support programs for the prevention of obesity in children and adults. The way in which the issue is framed is essential; support is highest when the tax is introduced in the context of promoting health and when the revenues are earmarked for programs promoting childhood nutrition or obesity prevention.

\section{CONCLUSIONS}

The federal government, a number of states and cities, and some countries (e.g., Mexico ${ }^{8}$ ) are considering levying taxes on sugar-sweetened beverages. The reasons to proceed are compelling. The science base linking the consumption of sugarsweetened beverages to the risk of chronic diseases is clear. Escalating health care costs and the rising burden of diseases related to poor diet create an urgent need for solutions, thus justifying government's right to recoup costs.

As with any public health intervention, the precise effect of a tax cannot be known until it is implemented and studied, but research to date suggests that a tax on sugar-sweetened beverages would have strong positive effects on reducing consumption. ${ }^{5,33}$ In addition, the tax has the potential to generate substantial revenue to prevent obesity and address other external costs resulting from the consumption of sugar-sweetened beverages, as well as to fund other healthrelated programs. Much as taxes on tobacco products are routine at both state and federal levels because they generate revenue and they confer a public health benefit with respect to smoking rates, we believe that taxes on beverages that help drive the obesity epidemic should and will become routine.

Supported in part by grants from the Rudd Foundation (to Dr. Brownell), the National Institutes of Health (R01-CA121152, to Dr. Popkin), and the Robert Wood Johnson Foundation (to Dr. Chaloupka).

No potential conflict of interest relevant to this article was reported.

From the Rudd Center for Food Policy and Obesity, Yale University, New Haven, CT (K.D.B.); the Department of Health and Mental Hygiene, City of New York, New York (T.F.); the Department of Nutrition, Harvard School of Public Health (W.C.W.), and the Optimal Weight for Life Program, Children's Hospital, and Harvard Medical School (D.S.L.) - all in Boston; the Department of Nutrition and the University of North Carolina Interdisciplinary Obesity Center, University of North Carolina, Chapel Hill (B.M.P.); the Department of Economics and the University of Illinois at Chicago Health Policy Center, University of Illinois, Chicago (F.J.C.); and the University of Arkansas for
Medical Sciences and the Surgeon General's Office, State of Arkansas, Little Rock (J.W.T.).

This article (10.1056/NEJMhpr0905723) was published on September 16, 2009, and was updated on March 31, 2010, at NEJM.org.

1. Malik VS, Schulze MB, Hu FB. Intake of sugar-sweetened beverages and weight gain: a systematic review. Am J Clin Nutr 2006;84:274-88.

2. Vartanian LR, Schwartz MB, Brownell KD. Effects of soft drink consumption on nutrition and health: a systematic review and meta-analysis. Am J Public Health 2007;97:667-75.

3. Fung TT, Malik V, Rexrode KM, Manson JE, Willett WC, Hu FB. Sweetened beverage consumption and risk of coronary heart disease in women. Am J Clin Nutr 2009;89:1037-42.

4. Brownell KD. Get slim with higher taxes. New York Times. December 15, 1994:A29.

5. Brownell KD, Frieden TR. Ounces of prevention - the public policy case for taxes on sugared beverages. N Engl J Med 2009; 360:1805-8.

6. Jacobson MF, Brownell KD. Small taxes on soft drinks and snack foods to promote health. Am J Public Health 2000;90: 854-7.

7. Powell LM, Chaloupka FJ. Food prices and obesity: evidence and policy implications for taxes and subsidies. Milbank Q 2009; 87:229-57.

8. Barquera S, Hernandez-Barrera L, Tolentino ML, et al. Energy intake from beverages is increasing among Mexican adolescents and adults. J Nutr 2008;138:2454-61.

9. Duffey KJ, Popkin BM. Shifts in patterns and consumption of beverages between 1965 and 2002. Obesity (Silver Spring) 2007; 15:2739-47.

10. Forshee RA, Anderson PA, Storey ML. Sugar-sweetened beverages and body mass index in children and adolescents: a metaanalysis. Am J Clin Nutr 2008;87:1662-71. [Erratum, Am J Clin Nutr 2009;89:441-2.]

11. Malik VS, Willett WC, Hu FB. Sugar-sweetened beverages and BMI in children and adolescents: reanalyses of a meta-analysis. Am J Clin Nutr 2009;89:438-9.

12. Ludwig DS, Peterson KE, Gortmaker SL. Relation between consumption of sugar-sweetened drinks and childhood obesity: a prospective, observational analysis. Lancet 2001;357:505-8.

13. Schulze MB, Manson JE, Ludwig DS, et al. Sugar-sweetened beverages, weight gain, and incidence of type 2 diabetes in young and middle-aged women. JAMA 2004;292:927-34.

14. Tordoff MG, Alleva AM. Effect of drinking soda sweetened with aspartame or high-fructose corn syrup on food intake and body weight. Am J Clin Nutr 1990;51:963-9.

15. Raben A, Vasilaras TH, Moller AC, Astrup A. Sucrose compared with artificial sweeteners: different effects on ad libitum food intake and body weight after $10 \mathrm{wk}$ of supplementation in overweight subjects. Am J Clin Nutr 2002;76:721-9.

16. James J, Thomas P, Cavan D, Kerr D. Preventing childhood obesity by reducing consumption of carbonated drinks: cluster randomised controlled trial. BMJ 2004;328:1237. [Erratum, BMJ 2004;328:1236.]

17. Sichieri R, Paula Trotte A, de Souza RA, Veiga GV. School randomised trial on prevention of excessive weight gain by discouraging students from drinking sodas. Public Health Nutr 2009;12:197-202.

18. Ebbeling CB, Feldman HA, Osganian SK, Chomitz VR, Ellenbogen SJ, Ludwig DS. Effects of decreasing sugar-sweetened beverage consumption on body weight in adolescents: a randomized, controlled pilot study. Pediatrics 2006;117:673-80.

19. Albala C, Ebbeling CB, Cifuentes M, Lera L, Bustos N, Ludwig DS. Effects of replacing the habitual consumption of sugarsweetened beverages with milk in Chilean children. Am J Clin Nutr 2008;88:605-11.

20. Montonen J, Järvinen R, Knekt P, Heliövaara M, Reunanen A. 
Consumption of sweetened beverages and intakes of fructose and glucose predict type 2 diabetes occurrence. J Nutr 2007;137: 1447-54.

21. Palmer JR, Boggs DA, Krishnan S, Hu FB, Singer M, Rosenberg L. Sugar-sweetened beverages and incidence of type 2 diabetes mellitus in African American women. Arch Intern Med 2008;168:1487-92.

22. Appel LJ, Sacks FM, Carey VJ, et al. Effects of protein, monounsaturated fat, and carbohydrate intake on blood pressure and serum lipids: results of the OmniHeart randomized trial. JAMA 2005;294:2455-64.

23. Ludwig DS. The glycemic index: physiological mechanisms relating to obesity, diabetes, and cardiovascular disease. JAMA 2002;287:2414-23.

24. Yoshida M, McKeown NM, Rogers G, et al. Surrogate markers of insulin resistance are associated with consumption of sugar-sweetened drinks and fruit juice in middle and older-aged adults. J Nutr 2007;137:2121-7.

25. Mourao DM, Bressan J, Campbell WW, Mattes RD. Effects of food form on appetite and energy intake in lean and obese young adults. Int J Obes (Lond) 2007;31:1688-95.

26. De Castro JM. The effects of the spontaneous ingestion of particular foods or beverages on the meal pattern and overall nutrient intake of humans. Physiol Behav 1993;53:1133-44.

27. Harnack L, Stang J, Story M. Soft drink consumption among US children and adolescents: nutritional consequences. J Am Diet Assoc 1999;99:436-41.

28. Flood JE, Roe LS, Rolls BJ. The effect of increased beverage portion size on energy intake at a meal. J Am Diet Assoc 2006; 106:1984-90.

29. Cawley J. An economic framework for understanding physical activity and eating behaviors. Am J Prev Med 2004;27:117-25.
30. Finkelstein EA, Ruhm CJ, Kosa KM. Economic causes and consequences of obesity. Annu Rev Public Health 2005;26:23957.

31. Finkelstein EA, Trogdon JG, Cohen JW, Dietz W. Annual medical spending attributable to obesity: payer-and-servicespecific estimates. Health Aff (Millwood) 2009;28:w822-w831. 32. Chaloupka FJ, Peck RM., Tauras JA, Yurekli A. Cigarette excise taxation: the impact of tax structure on prices, revenues, and cigarettes smoking. Geneva: World Health Organization (in press).

33. Andreyeva T, Long MW, Brownell KD. The impact of food prices on consumption: a systematic review of research on price elasticity of demand for food. Am J Public Health (in press).

34. Mattes RD, Popkin BM. Nonnutritive sweetener consumption in humans: effects on appetite and food intake and their putative mechanisms. Am J Clin Nutr 2009;89:1-14.

35. Rudd Center for Food Policy and Obesity. Revenue calculator for soft drink taxes. (Accessed September 24, 2009, at http:/l www.yaleruddcenter.org/sodatax.aspx.)

36. Brownell KD, Warner KE. The perils of ignoring history: big tobacco played dirty and millions died: how similar is big food? Milbank Q 2009;87:259-94.

37. Hakim D, McGeehan P. New York vulnerable to poaching in recession. New York Times. March 1, 2009.

38. Americans Against Food Taxes home page. (Accessed September 24, 2009, at http://nofoodtaxes.com.)

39. Brownell KD. The chronicling of obesity: growing awareness of its social, economic, and political contexts. J Health Polit Policy Law 2005;30:955-64.

Copyright $\odot 2009$ Massachusetts Medical Society. 